\title{
Design and Implementation of Bank Client Information Management System Based on Web
}

\author{
Dehai Qiu and Ziyan Yang \\ Jiangxi College of Foreign Studies
}

Keywords: Bank; Client information; Management system; Based on Web

\begin{abstract}
Bank clients' information management is a computer application system to manage the information of all the bank's clients in the bank's operation environment, and its basic functions include: to construct a unified diagram containing the information of all the bank's clients as well as provide timely and consistent client information access services for the operation system of the headquarter and its branches at different levels. Banks' client information management system is gradually becoming an essential part of the bank's information management. This paper introduces the development of a bank client information management system based on Web. Firstly, it elaborates on the concept of client information management system, and then introduces some common information technologies of the banking industry, including database, network technology and ASP.NET programme development technology. All these are the technical basis to develop bank client information management system.
\end{abstract}

\section{Introduction}

With China's accession to the WTO and the gradual deepening of the reform of the financial system, China's banks are facing unprecedented pressure from competition. After China's entry into the WTO, China's banking industry is faced with the more severe challenge from foreign financial institutions, so how to change the operation concept, deepen the connotation of services, improve the means of services and improve competitiveness will be the key to the sustainable development of the banking industry in the new century.

Ever since the reform and opening up, banks not only provide loan businesses, but also add various types of financial derivative business, which has expanded the financial channels for both banks and clients as well as improved banks' service quality. Meanwhile, with the rapid development of the computer technology, network technology as well as the communication technology, banks use these technologies to realize great innovation in management. This paper conducts in-depth research into the current status of managing client information at banks, designs a Web-based bank client information management system, and then analyzes the functions and demands of bank resources management system according to the ideology and method of software engineering and development to divide it into sub-systems and then conducts the overall design from two aspects: the system's function structure and technical structure.

Overview of Client Information Management System. Information management system is based on humans to transmit, collect, process, store, maintain and update information through computer software, hardware, the Internet and other office software so as to finally improve enterprises' efficiency, effectiveness and competitiveness, provide basis for enterprises in decision-making, controlling and operation and help enterprises to realize the planned integrated human-machine system.

Information Management System Contains Three Elements. Systematic View .Due to the MIS system to process information is an important part of the organization system, so the system is integration system; system is taking technology of the computer based man-machine system; the processing management information does not exist in isolation, in the system, its research object is an important part of the social system. 


\section{Mathematical Method}

The various models used in information processing are based on the mathematical model. On the one hand, the system can provide the basic data for the decision maker on the other hand it can provide the decision model for the decision maker through the knowledge and the mathematical model.

Application of Computer and Network Technology. MIS system is an important field of computer science and network science. From point of view the system development process, the system used by the technology mainly through the following three stages: CMC version of the system, the structure of the system, the structure of the system. These three stages cannot be separated from the support of computer and network technology.

Analysis of the Demand for Bank Client Information System. The bank customer information symbol system objective is to establish a safe and stable, convenient and practical system and meet the banking and auspice information processing requirements, improve the information management level of bank, specifically including:

(1) Bank staffs can quickly master this system. The interface is simple and pretty with strong operation and certain capacity to tolerate errors while being practical.

(2) The system's operation is stable, safe and reliable.

(3) Information query is flexible, convenient, quick and accurate, and data storage is safe and reliable.

(4) The system must establish a perfect safety guarantee system to control access to the system, login of the system and distribution of various operations' rights. In addition, during operating data, it is necessary to have a perfect sub-set of the system as well as the function of data recovery and recording logs.

(5) The system's data must be confidential, which is realized through setting different users.

\section{Overall Design of the System}

Design of the System's Frame. The system operation mode and function framework of the banking system are built with a certain scale, basically have their Web site, and through the high-speed line to Internet. Therefore, the bank can make system construction using Web own application mode. All the bank branches and mobile office users can directly through the Internet system and business operation is complete. Design of bank customer relationship management information system based on the use of advanced IT technology, combined with modern bank management idea, modern management mechanism construction in twenty-first Century. In the business process we break the limitation of the traditional information management, involved in the business data are unified management, according to the system user authority responsible for, reduce duplication of investment, realize the connection and cohesion between the customer and the bank's work is very good. To ensure the accuracy and timeliness of the information in the bank work, effectively ensure the high quality and efficiency of the bank customer relationship development work, to achieve the overall management of the bank customer information. The overall framework is shown in Fig. 1: 


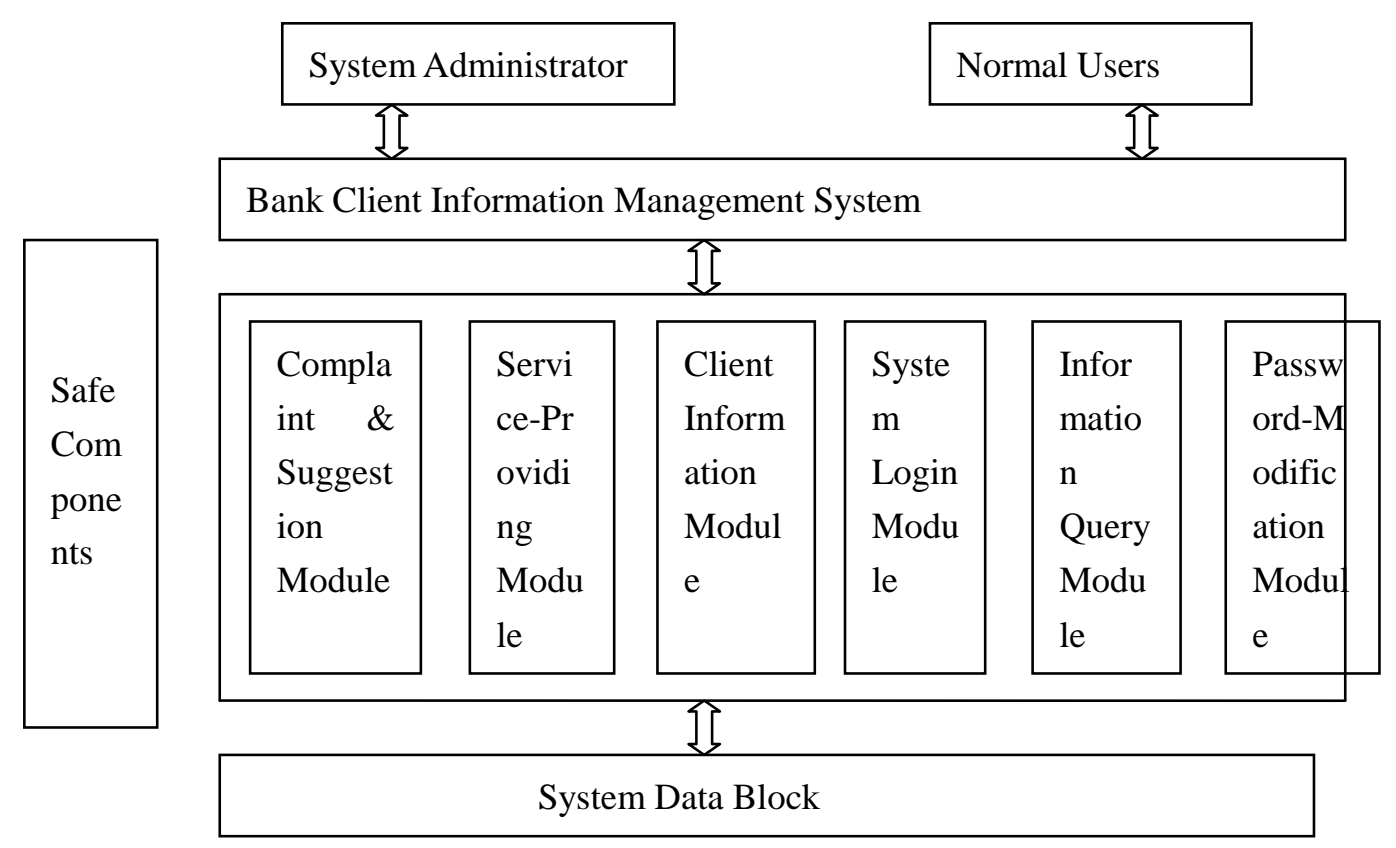

Figure 1. Overall Framework of Bank Client Information Management System

Logical Structure of the System. In terms of the software system, on the one hand, it can break down to the complexity of the problem management, and on the other hand, it also requires to effectively reuse the business logic and retain and database of important connection, therefore, the system uses B / S mode, the whole system is divided as three independent package, that is, the user that layer, business logic layer and data access layer. The main consideration of business logic is the realization of the function of the system, and the technical logic is the technical scheme of the formation of the user interface, the database or the communication mechanism. In the design of system architecture, we will interface all forms and components in the presentation layer, all business rules and logic implementation package in charge of business logic components, and the entire database interaction package in the data access component. Its structure is shown in Fig. 2:

Demonstration Level Business Logic Level Data Access Level Database

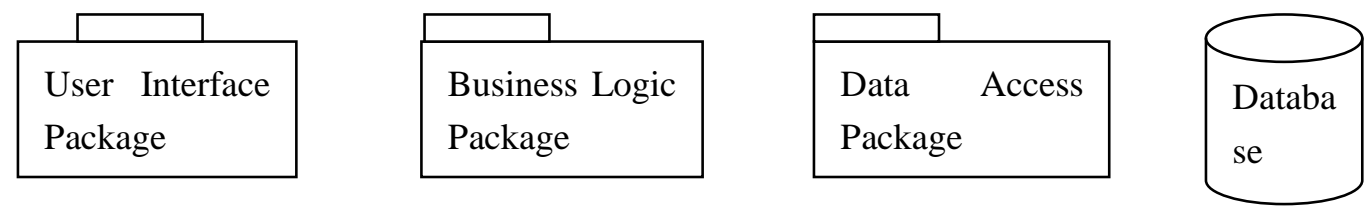

Figure 2. Three-layer Structure Diagram

The three-layer structure is of strict layering. The data access level can only be visited by the business logic level, and the business logic level can only be visited by the demonstration level. Users send requests of the demonstration level to the business logic level, and then business logic level will complete relevant business rules and logic, and obtain data by accessing database through the data access level. Then, data are shown at the demonstration level according to the adverse order.

\section{Conclusion}

Nowadays, as e-commerce is gradually penetrated into all fields of the society, both emerging industries and traditional industries are faced with new challenges and opportunities. Clients are the most valuable resources among all the resources, and clients' satisfaction is the key for the survival 
of banks. Banks' main competitive advantages lie in classifying clients and providing personalized services to each client. In the research in this paper, the author first defines the connotation of client relationship information management, which does not mean to establish a concrete systematic module, but aims at establishing a perfect data storage, processing and analyzing system so as to maximize the usage of unifying the management of clients' information.

\section{References}

[1] Slivka B W, Webber J S. Method for identifying and obtaining computer software from a network computer: US, US6049671 [P]. 2000.

[2] Schneidewind N F. Analysis of error processes in computer software [J]. Acm Simple Notices, 1975, 10(6).337-346.

[3] Liu X, Chang C K, Jiang T M, et al. Computer software and applications [J]. Journal of Systems \& Software, 2010, 83(2).12-22.

[4] Zhao Z J, Liu T. Design and Implementation of Bank Site Management System Based on ArcIMS Web ADF [J]. Geomatics \& Spatial Information Technology, 2012.

[5] Du B. The Design and Implementation of Enrollment and Employment Information Management System based on Web [J]. Applied Mechanics \& Materials, 2014, 687-691:1938-1941.

[6] Qystein Moen. Internationalization of small, computer software firms: Entry forms and market selection [J]. European Journal of Marketing, 2004, 38(9/10).1236-1251.

[7] TANG Yu-fang, ZHANG Yong-sheng. Design and Implementation of College Student Information Management System Based on Web Services[C]// 2009 ieee international symposium on it in medicine \& education. 2009:1044-1048.

[8] Koch H S, Kubat P. Optimal Release Time of Computer Software.[J]. IEEE Transactions on Software Engineering, 1983, 9(3).323-327.

[9] Li F, Lu K, Xie L, et al. Design and Realization of On-line Bank Customer Management System Based on Mainframe[C]// Wireless Communications, Networking and Mobile Computing, 2008. WiCOM '08. 4th International Conference on. IEEE, 2008:1-4.

[10]Lin S, Xu J, Li Z, et al. Design and Implementation of Lujiazui Land Management Information System Based on WebGIS[C]// International Conference on E-Business and E-Government. IEEE, 2010:667-670.

[11] Alkhateeb F, Manasrah A M, Bsoul AA R. Bank Web Sites Phishing Detection and Notification System Based on Semantic Web technologies [J]. International Journal of Security \& Its Applications, 2012, 6(4) :53-66.

[12]Zhang J W. Design and Implementation of the System Based on the Mobile Payment System of Traffic Violation Query and Pay a Fine [J]. Information Security \& Technology, 2013. 